\title{
Acid Gastroesophageal Reflux in Convalescent Preterm Infants: Effect of Posture and Relationship to Apnea
}

\author{
RAVINDRA Y. BHAT, GERRARD F. RAFFERTY, SIMON HANNAM, AND ANNE GREENOUGH \\ Division of Asthma, Allergy and Lung Biology, MRC-Asthma Centre, King's College London School of Medicine, \\ London, United Kingdom SE5 9RS
}

\begin{abstract}
Concerns regarding gastroesophageal reflux (GER) and associated apnea episodes result in some practitioners having convalescent, prematurely born infants sleep in the prone position. We have tested the hypothesis that such infants would not suffer from clinically important acid GER or associated apnea episodes more in the supine compared with the prone position. Lower esophageal $\mathrm{pH}$ was measured and videopolysomnographic recordings of nasal airflow, chest and abdominal wall movements, electrocardiographic activity, and oxygen saturation were made on two successive days of 21 premature infants (median gestational age $28 \mathrm{wk}$ ) at a median postmenstrual age (PMA) of $36 \mathrm{wk}$. On each day, the infants were studied prone and supine. The acid reflux index was higher in the supine compared with the prone position (median $3 \%$ versus $0 \%, p=$ 0.002 ), but was low in both positions. The number of obstructive apnea episodes per hour was higher in the supine position ( $p=$ 0.008). There were, however, no statistically significant correlations between the amount of acid GER and the number of either obstructive or total apnea episodes in either the supine or prone position. Supine compared with prone sleeping neither increases clinically important acid GER nor obstructive apnea episodes associated with acid GER in asymptomatic, convalescent, prematurely born infants. (Pediatr Res 62: 620-623, 2007)
\end{abstract}

$\mathrm{P}$ rematurely born infants are at increased risk of sudden infant death syndrome (SIDS), particularly if they sleep in the prone position (1). Despite this known adverse association, some prematurely born infants still sleep in the prone position at the age when they are at highest risk of SIDS (2). Several studies have highlighted that parents are strongly influenced by health care practitioners with regard to their choice of sleeping position for their infant $(3,4)$. Worryingly, the results of a national survey (5) revealed that in some neonatal units, prematurely born infants slept in the prone position even just before discharge from the neonatal intensive care unit (NICU). One of the reasons given for continuation of prone sleeping is the perceived increased risk of gastroesophageal reflux (GER) in the supine position (6) and that the likelihood of associated problems such as apnea may be less in the prone position. Yet, it is known that there is maturation of the reflexes that protect against GER and esophagopharyngeal reflux (7). Esophageal and upper esophageal sphincter motor responses to abrupt

Received March 21, 2007; accepted June 17, 2007.

Correspondence: Anne Greenough, M.D., Department of Child Health, 4th Floor, Golden Jubilee Wing, King's College Hospital, Bessemer Road, London, SE5 9RS, UK; e-mail: anne.greenough@kcl.ac.uk

Dr. Bhat was supported by King's College Hospital Joint Research Committee. mid-esophageal provocation are present as early as $33 \mathrm{wk}$ PMA, and the response characteristics improve during development (7). We, therefore, hypothesized that convalescent, asymptomatic, prematurely born infants ready for NICU discharge would not suffer from either clinically important acid GER or apnea episodes associated with acid GER more in the supine compared with the prone position. The aim of this study was to test that hypothesis by investigating the influence of sleeping position on acid reflux and any association with apnea episodes. In certain studies $(8,9)$, but not all $(10)$, a significant relationship between bronchopulmonary dysplasia (BPD) and GER has been reported. As a consequence, we recruited infants with and without $\mathrm{BPD}$, to determine whether BPD status influenced our findings.

\section{METHODS}

Infants born at $<33$ wk of gestation who were being prepared for discharge were eligible for entry into this study. When the infants were tolerating three hourly feeds, their parents were approached and the study design explained. If informed written consent was obtained, infants were studied on two successive days. Six sets of parents refused consent, the demographics of their infants did not differ significantly from the 21 who did take part (data not shown). On each day, infants were examined in both the supine and prone position each for $3 \mathrm{~h}$. The order in which the positions were examined was randomized between babies, and on the following day, the positions were examined in an individual baby in the opposite order. The results obtained from a particular position on the two study days were averaged. In each position, lower esophageal $\mathrm{pH}$ was measured and videopolysomnographic recordings of nasal airflow, chest, and abdominal wall movements were made.

Lower esophageal $\mathrm{pH}$ was measured using a $\mathrm{pH}$ probe (Digitrapper MK 111 Gold pH meter, Synerics Medical, Middlesex, UK). To appropriately position the $\mathrm{pH}$ probe, $85 \%$ of the predicted length according to Strobel's formula (11) was used for infants longer than $40 \mathrm{~cm}$, and a nomogram was used (12) for infants $<40 \mathrm{~cm}$. Chest radiographs were not taken. An acid reflux index was calculated, which is the percentage of the study time the esophageal $\mathrm{pH}$ was $<4$ (13). An acid reflux index $>12 \%$ was considered clinically significant, as that is the level at which treatment would be considered (13). In addition, acid GER episodes during which the $\mathrm{pH}$ drop was $>1 \mathrm{pH}$ unit were identified.

Videopolysomnographic recordings of nasal airflow, chest and abdominal wall movements, limb movements, electrocardiographic activity, and oxygen saturation were made using an Alice 4 sleep study system (Respironics Marietta, Marietta, GA). Thoracic and abdominal respiratory movements were measured by impedance and airflow was measured with thermistors taped under both nostrils. Gross body movements were assessed using two activity meters attached to the upper and lower limbs as well as by video. Oxygen saturation was measured continuously with a pulse oximeter (Datex Omeda 3900); desaturations were considered significant if the oxygen saturation decreased to $<90 \%$ (14). The data were collected with a computerized sleep recorder (Alice Recording System). Each recording was examined to

Abbreviations: BPD, bronchopulmonary dysplasia; GER, gastroesophageal reflux 
determine whether the infant had had apnea episodes during the period of sleep. Apnea episodes were defined as a pause in respiration indicated by a lack of nasal airflow of at least $5 \mathrm{~s}$ (15). A subanalysis of apnea episodes $>10 \mathrm{~s}$ was also undertaken for the whole cohort. Apneas were classified as obstructive if, despite chest and abdominal wall movements, there was no nasal airflow, central if there was no nasal airflow and an absence of chest and abdominal wall movements, and mixed if there was a combination of central and obstructive apnea episodes. An apnea index (the number of apnea episodes per hour of sleep) was calculated for each type of apnea, as we have previously demonstrated convalescent, prematurely born infants have greater sleep efficiency, i.e. sleep longer per study period, in the prone compared with the supine position (14)

Analysis. Differences between positions were assessed for statistical significance using the paired Wilcoxon rank-sum test or Mann-Whitney $U$ test as appropriate. To determine the strength of relationships between the reflux index and apnea episodes, Spearman's correlation coefficients were calculated. In addition, an apnea index related to $\mathrm{pH}$, i.e. the number of apnea episodes when the $\mathrm{pH}$ was either $>4$ or $<4$, was calculated for obstructive or mixed apnea episodes. In each position, this apnea index related to $\mathrm{pH}$ was compared with determine whether the index was greater when the $\mathrm{pH}$ was $>4$ or $<4$. The number of apnea episodes (per hour of sleep) associated with significant desaturations was also compared when the $\mathrm{pH}$ was $>4$ or $<4$. Significant desaturations were deemed to be associated with an apnea if they occurred during or in the $3 \mathrm{~s}$ following an apnea.

Sample size. Recruitment of 21 infants, each studied in both the supine and prone positions, allowed detection of differences between the supine and prone positions equal to at least $1 \mathrm{SD}$ of the measurements with $90 \%$ power at the $5 \%$ level.

Patients. Twenty-one infants with a median gestational age at birth of 27.9 wk (range, 24.9-32.0) wk and birth weight range of 660-1614 g were studied at a median PMA of $36.3 \mathrm{wk}$ (range, 34.6-40.7). Twelve of the infants were oxygen dependent and had or subsequently fulfilled the diagnosis of BPD (oxygen dependency beyond 36 wk PMA), their median gestational age at birth (26.9 g; range, 24.9-29.6), and birth weight (814 g; range, 660-1370) were lower than that of the nine non-BPD infants [median gestational age at birth of $31 \mathrm{wk}$ (range, 26.6-32) and birth weight of $1164 \mathrm{~g}$ (range, 828 $1614)]$ ( $p=0.003$ and $p=0.003$, respectively). The two groups were studied at similar median PMAs (37.2 wk; range, 35.4-40.7 in BPD infants and 36.3 wk; range, $34.6-40.1$ in non-BPD infants) $(p=0.24)$. None of the infants were receiving methylxanthines or treatment for GER, but one of the BPD infants was receiving diuretics. All the infants were receiving three hourly feeds and had nasogastric tubes in situ. In each position, the 3-h study period began after they had received a feed. Some of the patients' apnea results have been previously reported (14). Parents gave informed written consent for their infant to take part in the study, which was approved by the King's College Hospital Research Ethics Committee.

\section{RESULTS}

In the cohort overall, the reflux index $(p=0.002)$ was higher in the supine than the prone position (Table 1). The reflux index, however, was low in both positions (Table 1), the $\mathrm{pH}$ being $<4$ only for a median of 4 min (range, $0-20.2$ ) in the supine position and $0 \mathrm{~min}$ (range, $0-14.7$ ) in the prone position $(p=0.01)$. Obstructive $(p=0.008)$ and mixed $(p=$ $0.03)$ apnea episodes $(>5 \mathrm{~s})$ were more common in the supine position. There were very few apnea episodes $>10 \mathrm{~s}$, and there were no significant differences in the apnea indexes for apnea episodes $>10 \mathrm{~s}$ according to position (Table 2). In the BPD infants, the reflux index $(p=0.03)$ was higher and obstructive apnea episodes more common $(p=0.04)$ in the supine position, but central apnea episodes were more common in the prone position $(p=0.02)$ (Table 1). In the non-BPD infants, only the reflux index differed significantly between positions and was higher in the supine position ( $p=$ 0.03 ) (Table 1). There were no significant differences in the amount of acid reflux in either the prone or supine position between the BPD and non-BPD infants (prone position BPD infants: median $1.75 \%$ versus non-BPD infants $0 \%, p=$
Table 1. Comparison of apnea episodes $(>5 s)$ and reflux indexes in the prone and supine positions

\begin{tabular}{|c|c|c|c|}
\hline & Prone & Supine & $p$ \\
\hline \multicolumn{4}{|l|}{ Overall } \\
\hline Recording time (min) & $161(134-180)$ & $163(130-192)$ & ns \\
\hline Sleeping time (min) & $144(103-164)$ & $117(103-164)$ & 0.0002 \\
\hline $\begin{array}{l}\text { Central apnea episodes } \\
\text { (per hour of sleep) }\end{array}$ & $5.7(0.2-22.6)$ & $2.3(0-67.13)$ & ns \\
\hline $\begin{array}{l}\text { Obstructive apnea episodes } \\
\text { (per hour of sleep) }\end{array}$ & $0.4(0-5.8)$ & $1.1(0-5.8)$ & 0.008 \\
\hline $\begin{array}{l}\text { Mixed apnea episodes } \\
\text { (per hour of sleep) }\end{array}$ & $1.9(0-18.4)$ & $5.2(0-12.7)$ & 0.03 \\
\hline Reflux index $(\%)$ & $0(0-11.4)$ & $3(0-15.4)$ & 0.002 \\
\hline \multicolumn{4}{|l|}{ BPD infants } \\
\hline $\begin{array}{l}\text { Central apnea episodes } \\
\text { (per hour of sleep) }\end{array}$ & $2.6(0.2-22.6)$ & $1.4(0-10.6)$ & 0.02 \\
\hline $\begin{array}{l}\text { Obstructive apnea episodes } \\
\text { (per hour of sleep) }\end{array}$ & $0.7(0-1.9)$ & $1.9(0-5.8)$ & 0.01 \\
\hline $\begin{array}{l}\text { Mixed apnea episodes } \\
\text { (per hour of sleep) }\end{array}$ & $1.5(0-18.4)$ & $5.3(0-8.9)$ & $\mathrm{ns}$ \\
\hline Reflux index $(\%)$ & $1.8(0-11.4)$ & $3(0-15.4)$ & 0.03 \\
\hline \multicolumn{4}{|l|}{ Non-BPD infants } \\
\hline $\begin{array}{l}\text { Central apnea episodes } \\
\text { (per hour of sleep) }\end{array}$ & $9.1(4.6-16.2)$ & $7.7(1.7-67.1)$ & $\mathrm{ns}$ \\
\hline $\begin{array}{l}\text { Obstructive apnea episodes } \\
\text { (per hour of sleep) }\end{array}$ & $0.2(0-5.8)$ & $0.6(0-4.2)$ & ns \\
\hline $\begin{array}{l}\text { Mixed apnea episodes } \\
\text { (per hour of sleep) }\end{array}$ & $2.8(0.5-8.1)$ & $4.9(0-12.7)$ & ns \\
\hline Reflux index $(\%)$ & $0(0-6.4)$ & $6.5(0-10)$ & 0.03 \\
\hline
\end{tabular}

Data are demonstrated as median (range). ns, not significant.

Table 2. Comparison of apnea episodes $>10 \mathrm{~s}$ in the prone and supine positions

\begin{tabular}{|c|c|c|c|}
\hline & Prone & Supine & $p$ \\
\hline $\begin{array}{l}\text { Central apnea episodes } \\
\text { (per hour of sleep) }\end{array}$ & $0.5(0-1.5)$ & $0(0-6.8)$ & ns \\
\hline $\begin{array}{l}\text { Obstructive apnea episodes } \\
\text { (per hour of sleep) }\end{array}$ & $0(0-0.9)$ & $0(0-1)$ & $\mathrm{ns}$ \\
\hline $\begin{array}{l}\text { Mixed apnea episodes } \\
\text { (per hour of sleep) }\end{array}$ & $0.46(0-2)$ & $0.43(0-2.1)$ & $\mathrm{ns}$ \\
\hline
\end{tabular}

0.085; supine position BPD infants: median $3 \%$ versus nonBPD infants $6.5 \%, p=0.75)$.

In neither the supine $(p=0.27)$ nor the prone $(p=0.27)$ position were there significant correlations between the reflux index and total apnea episodes or between the reflux index and obstructive apnea episodes (supine: $p=0.55$, prone: $p=$ 0.39 ). In addition, there were no significant correlations between the acid GER episodes in which the $\mathrm{pH}$ fell by $>1 \mathrm{pH}$ unit and either total ( $p=0.78$ supine, $p=0.09$ prone), or obstructive ( $p=0.1$ supine, $p=0.08$ prone) apnea episodes in either position. There was no significant difference in the number of acid GER episodes in which the $\mathrm{pH}$ fell by $>1 \mathrm{pH}$ unit between positions ( $n=18$; range, $5-41$ prone; $n=18$, range, $9-35$ supine) $(p=0.7)$, nor was there a significant difference in the number of such episodes in the two positions in the first postprandial hour (prone: $n=6$; range, $1-20$; supine: $n=7$; range, $2-19)(p=0.7)$. There were very few apnea episodes ( $>5 \mathrm{~s}$ ) associated with an esophageal $\mathrm{pH}<4$ in either position (Table 3). Dividing the apnea episodes according to whether the $\mathrm{pH}$ was $>4$ or $<4$ four demonstrated 
Table 3. Occurrence of apnea episodes $>5 s$ (number per hour of sleep with the $\mathrm{pH}<4$ or $>4$ as appropriate) associated or not associated with $\mathrm{pH}<4$ related to position

\begin{tabular}{lccc}
\hline & Prone & Supine & $p$ \\
\hline $\mathrm{pH}<4$ & & & \\
Obstructive apnea & $0(0)$ & $0(0-6.3)$ & $\mathrm{ns}$ \\
Mixed apnea & $0(0-4.6)$ & $0(0-25)$ & 0.03 \\
$\mathrm{pH}>4$ & $0.2(0-6)$ & $0.6(0-7.1)$ & $\mathrm{ns}$ \\
Obstructive apnea & $1(0-11)$ & $3(0-7.9)$ & 0.02 \\
$\quad$ Mixed apnea & &
\end{tabular}

Data are presented as median (range).

Table 4. Occurrence of apnea episodes $>10$ s (number per hour of sleep with the $\mathrm{pH}<4$ or $>4$ as appropriate) associated or not associated with $\mathrm{pH}<4$ related to position

\begin{tabular}{llll}
\hline & Prone & Supine & $p$ \\
\hline $\mathrm{pH}<4$ & & & \\
Obstructive apnea & $0(0-0)$ & $0(0-1)$ & $\mathrm{ns}$ \\
$\quad$ Mixed apnea & $0(0-2)$ & $0(0-3)$ & $\mathrm{ns}$ \\
$\mathrm{pH}>4$ & & & \\
$\quad$ Obstructive apnea & $0(0-2)$ & $0(0-2)$ & $\mathrm{ns}$ \\
$\quad$ Mixed apnea & $1(0-4)$ & $1(0-5)$ & $\mathrm{ns}$ \\
\hline
\end{tabular}

Data are presented as median (range).

that mixed apnea episodes regardless of the esophageal $\mathrm{pH}$ were significantly higher in the supine compared with the prone position. There were very few apnea episodes $>10 \mathrm{~s}$ (Table 4), particularly when the $\mathrm{pH}<4$. There were no significant differences when the $\mathrm{pH}$ was either $>4$ or $<4$ in apnea indexes (for apnea episodes $>10 \mathrm{~s}$ ) according to position. There were only 25 apnea episodes associated with significant desaturations in the whole study. The only significant difference in the occurrence of episodes of obstructive or mixed apnea associated with significant desaturations was in the supine position, there were more mixed apnea episodes per hour associated with significant desaturations when the $\mathrm{pH}$ was greater rather than less than four $(p=0.01)$. There were, however, no significant differences in the occurrence of either type of apnea associated with significant desaturation between positions.

\section{DISCUSSION}

We have demonstrated that, in asymptomatic, convalescent, prematurely born infants, acid GER was more common in the supine rather than the prone position. In the majority of infants, however, the amount of acid reflux and time spent with a $\mathrm{pH}<4$ were low in both positions. Indeed, only one infant had an acid reflux level that would be considered for treatment (12), if the infant had been symptomatic. We have previously reported that episodes of obstructive and mixed apnea were more common in the supine position, whereas central apnea episodes were more common in the prone position (14). Mixed apnea episodes consist of central pauses and obstructive components and can be either centralobstructive or the reverse sequence. Obstructive apnea episodes occur partly due to a change in genioglossus muscle tone allowing the tongue to come in contact with the posterior part of the pharynx (16). It seems more likely that the tongue will fall backward in the supine rather than the prone position, increasing the likelihood of obstructive and mixed (obstructive-central) apnea episodes in the supine position. We now report that, despite obstructive and mixed apnea episodes ( $>5 \mathrm{~s})$ being more common in the supine position, there was no significant correlation between obstructive apnea episodes and acid reflux in either the prone or supine position. We did not show a significant association of sleeping position with any type of apnea lasting $>10 \mathrm{~s}$, but this likely reflects the very small number of apnea episodes of that duration in either position. We also did not demonstrate any significant correlations between acid GER episodes when the $\mathrm{pH}$ decrease was $>1 \mathrm{pH}$ unit and apnea episodes in either position. The apnea indexes for obstructive or mixed apnea episodes were not higher in either position when the $\mathrm{pH}$ was $<4$ rather than $>4$. Indeed, the apnea index for obstructive and mixed apnea episodes (apnea episodes $>5 \mathrm{~s}$ or $>10 \mathrm{~s}$ ) associated with a $\mathrm{pH}$ $<4$ was low in both sleeping positions (Tables 3 and 4, respectively). Our results are in keeping with those of a retrospective study (10) of clinically symptomatic infants referred for esophageal $\mathrm{pH}$ monitoring. No significant differences were found in the proportions of infants who had apnea between those with and without GER (10). Most other studies have also failed to document a temporal relationship between apnea and GER (17-23). We now highlight that there is no such relationship in either the prone or, importantly, the supine position in convalescent, prematurely born infants. We also demonstrate clinically significant desaturations related to apnea episodes were not more common in the supine position when the $\mathrm{pH}$ was $<4$.

To diagnose reflux, we used an esophageal $\mathrm{pH}$ monitor that detects acid reflux events. The main application is to detect occult GER causing extraesophageal symptoms (24). The sensitivity and specificity of esophageal $\mathrm{pH}$ monitoring for the detection and quantification of GER are $87 \%-93 \%$ and $93 \%-$ $97 \%$, respectively (25). In prematurely born infants, it has been suggested that this method of monitoring may not be that reliable, as GER cannot be detected when the gastric $\mathrm{pH}$ is $>4$, and in prematurely born infants, the gastric $\mathrm{pH}$ may be $>4$ for the majority of the time $(26,27)$. In this study, $\mathrm{pH}$ monitoring was used in both positions and, as there is no evidence to suggest esophageal $\mathrm{pH}$ monitoring function is influenced by sleeping position, our findings of differences in acid reflux between positions are robust.

BPD may predispose an infant to reflux because of transient increases in intra-abdominal pressure from forced exhalation related to coughing and crying and decreased lower esophageal sphincter pressure from flattened diaphragms. In addition, there may be increased gastric acid production; this can occur with medication such as methylxanthines (28), which can lower esophageal sphincter pressure (29) and worsen GER. In this study, we saw no significant differences in the amount of acid reflux between the BPD and non-BPD infants in either the prone or supine position. This is contrary to some earlier findings $(8,10)$. We studied 12 infants with BPD and required a sample size of 21 to detect differences between positions with $90 \%$ power; thus, our negative result may reflect a type II error. There are, however, other explanations for the differ- 
ences between the results of earlier studies $(8,10)$ and this study. In particular, our infants had no symptoms of GER, were about to be discharged from the NICU, and were not receiving medication likely to increase gastric production or alter lower esophageal sphincter pressure.

We have demonstrated that acid reflux is greater in the supine than the prone position in asymptomatic, convalescent, prematurely born infants about to be discharged from the NICU, but the amount of acid reflux was low in both positions. In addition, no significant association of acid reflux with obstructive or total apnea episodes was found. It has been highlighted (30) that airway protection is compromised in the prone position during active sleep as the swallowing rate was significantly reduced without a compensatory increase in arousal. We now demonstrate sleeping in the supine compared with prone position neither increases acid GER nor apnea episodes associated with acid GER in asymptomatic, convalescent, prematurely born infants. Our results and those previously published (30) give support to recommending supine sleeping for asymptomatic, convalescent, prematurely born infants.

Acknowledgments. The authors are grateful to Deirdre Gibbons for secretarial assistance and the King's College Hospital Joint Research Committee and the Foundation for the Study of Infant Death who provided the funding for the equipment.

\section{REFERENCES}

1. Oyen N, Markestad T, Skaerven R, Irgens LM, Helweg-Larson K, Alm B, Norvenius G, Wennergren G 1997 Combined effects of sleeping position and prenatal risk factors in sudden infant death syndrome: the Nordic Epidemiological SIDS Study. Pediatrics 100:613-621

2. Adams MM, Kugener B, Mirmiran M, Ariagno RL 1998 Survey of sleeping position after hospital discharge in healthy preterm infants. J Perinatol 18:168-172

3. Colson ER, Bergman DM, Shapiro E, Leventhal JH 2001 Position for newborn sleep: associations with parents' perceptions of their nursery experience. Birth 28:249-253

4. Vernacchio L, Corwin MJ, Lesko SM, Vezina RM, Hunt CE, Hoffman HJ, Willinger M, Mitchell AA 2003 Sleep position of very low birthweight infants. Pediatrics 111:633-640

5. Bhat RY, Leipala JA, Rafferty GF, Hannam S, Greenough A 2003 Survey on sleeping position recommendations for prematurely born infants on neonatal intensive care unit discharge. Eur J Pediatr 162:426-427

6. Blumenthal I, Lealman GT 1982 Effect of posture on gastro-oesophageal reflux in the newborn. Arch Dis Child 57:555-556

7. Jadcherla SR, Duong HQ, Hoffman RG, Shaker R 2003 Oesophageal body and upper oesophageal sphincter motor responses to oesophageal provocation during maturation in preterm newborns. J Pediatr 143:31-38
8. Hoyoux C, Forget P, Lambrechts L, Geubelle F 1985 Chronic bronchopulmonary dysplasia and gastroesophageal reflux in children. Pediatr Pulmonol 1:149-153

9. Hrabovsky EE, Mullett MD 1986 Gastroesophageal reflux and the premature infant. J Pediatr Surg 21:583-587

10. Akinola E, Rosenkrantz TS, Pappagallo M, McKay K, Hussain N 2004 Gastroesophageal reflux in infants $<32$ weeks gestational age at birth: lack of relationship to chronic lung disease. Am J Perinatol 21:57-62

11. Strobel C, Byrne WJ, Ament ME, Euler AR 1979 Correlation of esophageal lengths in children with height: application to the Tuttle test without prior esophageal manometry. J Pediatr 94:81-84

12. Omari TI, Benninga MA, Haslam RR, Barnett CP, Davidson GP, Dent J 1999 Lower esophageal sphincter position in premature infants cannot be correctly estimated with current formulas. J Pediatr 135:522-555

13. Rudolph CD, Mazur LJ, Liptak GS, Baker RD, Boyle JT, Colletti RB, Gerson WT, Werlin SL. North American Society for Pediatric Gastroenterology and Nutrition 2001 Guidelines for evaluation and treatment of gastroesophageal reflux in infants and children: recommendations of the North American Society for Pediatric Gastroenterology and Nutrition. J Pediatr Gastroenterol Nutr 32:S1-S31

14. Bhat RY, Hannam S, Pressler R, Rafferty GF, Peacock JL, Greenough A 2006 Effect of prone and supine position on sleep, apnoeas and arousals in preterm infants. Pediatrics 118:101-107

15. Upton CJ, Milner AD, Stokes GM 1991 Apnoea, bradycardia and oxygen saturation in preterm infants. Arch Dis Child 66:381-385

16. Brouillette RT, Thach BT 1979 A neuromuscular mechanism maintaining extrathoracic airway patency. J Appl Physiol 46:772-779

17. Walsh JK, Farrell MK, Keenan WJ, Lucas M, Kramer M 1981 Gastro-oesophageal reflux in infants: relation to apnea. J Pediatr 99:197-201

18. Newell SJ, Booth IW, Morgan ME, Durbin GM, McNeish AS 1989 Gastrooesophageal reflux in preterm infants. Arch Dis Child 64:780-786

19. Kahn A, Rebuffat E, Sottiaux M, Blum D, Yasik EA 1990 Sleep apneas and acid oesophageal reflux in control infants and in infant with apparent life-threatening events. Biol Neonate 57:144-149

20. Paton JY, Nanayakkara CS, Simpson H 1990 Observations on gastro-oesophageal reflux, central apnoea and heart rate in infants. Eur J Pediatr 149:608-612

21. Paton JY, Macfadyen U, Williams A, Simpson H 1990 Gastro-oesophageal reflux and apnoeic pauses during sleep in infancy - no direct relation. Eur J Pediatr 149:680-686

22. De Ajuriaguerra M, Radvanyi-Bouvet MF, Huon C, Moriette G 1991 Gastrooesophageal reflux and apnoea in prematurely born infants during wakefulness and sleep. Am J Dis Child 145:1132-1136

23. Arad-Cohen N, Cohen A, Tirosh E 2000 The relationship between gastrooesophageal reflux and apnea in infants. J Pediatr 137:321-326

24. Vijayaratnam V, Lin CH, Simpson P, Toha V 1999 Lack of proximal esophageal acid reflux in infants presenting with respiratory symptoms. Pediatr Pulmonol 27:231-235

25. Badriul H, Vandenplas Y 1999 Gastro-oesophageal reflux in infancy. J Gastroenterol Hepatol 14:13-19

26. Mitchell DJ, McClure BG, Tubman TR 2001 Simultaneous monitoring of gastric and oesophageal $\mathrm{pH}$ reveals limitations of conventional oesophageal $\mathrm{pH}$ monitoring in mild fed infants. Arch Dis Child 84:273-276

27. Grant L, Cochran D 2001 Can pH monitoring reliably detect gastro-oesophageal reflux in preterm infants. Arch Dis Child Fetal Neonatal Ed 85:F155-F157

28. Orenstein SR, Orenstein BM 1988 Gastro-oesophageal reflux and respiratory disease in children. J Pediatr 112:847-857

29. Stein MR, Towner GR, Weber RW, Mansfield ME, Jacobson KW, McDonnell JT, Nelson HS 1980 The effect of theophylline on the lower oesophageal sphincter pressure. Ann Allergy 45:238-241

30. Jeffery HE, Megevand A, Page M 1999 Why the prone position is a risk factor for sudden infant death syndrome. Pediatrics 104:263-269 